\title{
Central nervous system magnetic resonance imaging aspects of superficial siderosis
}

Aspectos da ressonância magnética do sistema nervoso central de siderose superficial Tarso Adoni', Eduardo Genaro Mutarelli², Jerusa Smid³, Luiz Antônio Pezzi Portela ${ }^{4}$

A 68-year-old man was evaluated with progressive gait difficulties, first noticed three years before. Neurological examination disclosed paraparetic spastic gait and lower limbs hyperreflexia with bilateral Babinski sign; mild left upper limb cerebellar ataxia; and left hearing loss. The magnetic resonance imaging (MRI) showed rims of hypointensity on T2 around the brainstem, cerebellum, and spinal cord, which was consistent with radiological diagnosis of superficial siderosis ${ }^{1}$ (Figs 1 to 3 ). There was no previous history of central nervous system (CNS) bleeding or trauma. Conventional angiographies were unremarkable. This rare case of primary superficial siderosis highlights the classic triad of hearing loss, ataxia, and myelopathy and its pathognomonic MRI findings ${ }^{2}$.

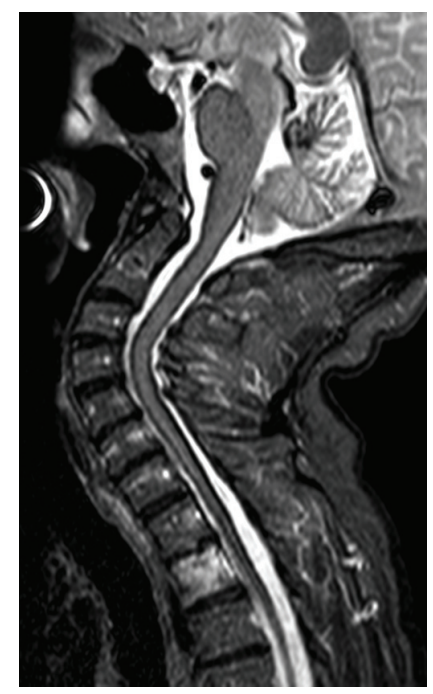

Fig 1. Sagittal T2 weighted image shows hypointense rim on spinal cord, medulla, pons, mamillary bodies, chiasm, mesencephalic tectum, and rostral cerebellar vermis.

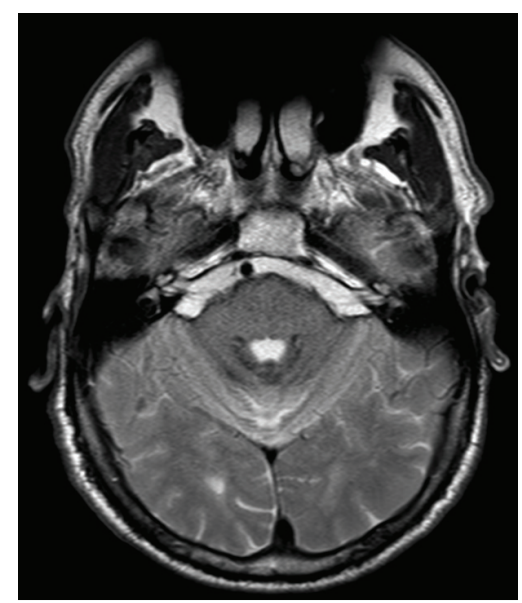

Fig 2. Axial T2 weighted image shows hypointense rim along the surface of pons and cerebellum, including the depth of its fissures.

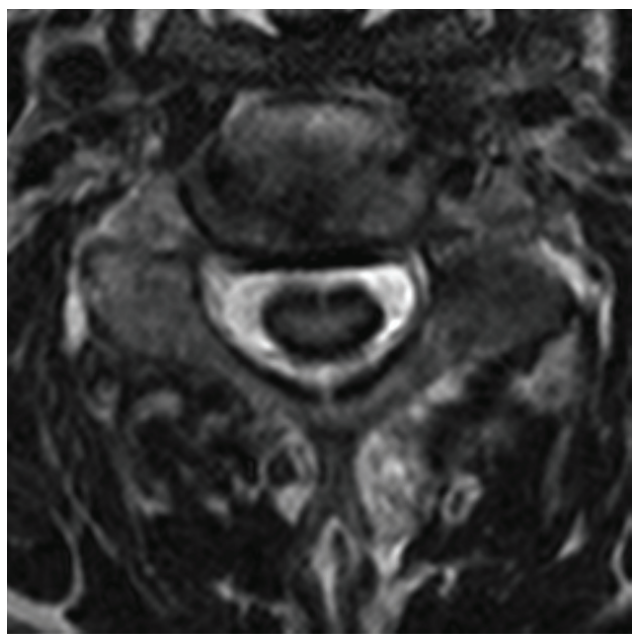

Fig 3. Axial T2 weighted image shows deeper impregnation of spinal cord tissue by hemosiderin deposits.
1. Kumar N. Neuroimaging in superficial siderosis: an in-depth look. AJNR Am J Neuroradiol 2010;31:5-14.
Kumar N, Cohen-Gadol AA, Wright RA, Miller GM, Piepgras DG, Ahlskog JE. Superficial siderosis. Neurology 2006;66:1144-1152.

${ }^{1} \mathrm{MD}$, PhD; Hospital Sírio-Libanês, São Paulo SP, Brazil;

${ }^{2} \mathrm{MD}$, PhD, Fellow of the American Academy of Neurology; Hospital Sírio-Libanês, São Paulo SP, Brazil;

${ }^{3} \mathrm{MD}$, PhD; University of São Paulo School of Medicine (FM-USP), São Paulo SP, Brazil;

${ }^{4} \mathrm{MD}$, PhD; Fleury Group of Diagnostic Medicine, São Paulo SP, Brazil.

Correspondence: Tarso Adoni; Rua Dona Adma Jafet 74 / conjunto 121;01308-050 São Paulo SP - Brasil; E-mail: tarso@dfvneuro.com.br

Conflict of interest: There is no conflict of interest to declare.

Received 23 May 2012; Received in final form 18 June 2012; Accepted 25 May 2012 